\title{
A Unitary Perspective for Cancer Nursing
}

Emiko Endo ${ }^{1^{*}}$, Mari Takaki ${ }^{2}$ and Tomoko Miyahara ${ }^{3}$

${ }^{1}$ Professor, Musashino University, Graduate School in Nursing, Japan

${ }^{2}$ Associate Professor, Musashino University, Graduate School in Nursing, Japan

${ }^{3}$ OCNS, Kanagawa Prefectural Cancer Center, Japan

“Corresponding author: Emiko Endo, Professor, Musashino University, Graduate School in Nursing, Japan, Tel: 81-42-468-3232; E-mail: emi_endo@musashinou.ac.jp

Received date: Nov 25, 2013, Accepted date: Feb 20, 2013, Published date: March 10, 2014

Copyright: (c) 2014 Endo, E, et al. This is an open-access article distributed under the terms of the Creative Commons Attribution License, which permits unrestricted use, distribution, and reproduction in any medium, provided the original author and source are credited.

\begin{abstract}
Purpose/Objectives: With development of innovative cancer diagnosis/treatment and increased cancer survivorship, the education of Oncology Advanced Practice Nurses (OAPN) is becoming increasingly complex, from the standpoint of both medical and nursing models. The purpose of this educational article is to address this issue and to present the authors' reflection on the educational practice with OAPN students in a unitary approach based on Margaret Newman's theory of health as expanding consciousness.
\end{abstract}

Data sources and data synthesis: The authors' journals and the students' descriptions of their practice were used, and the data was synthesized through dialogue among the authors and the OAPN students.

Conclusion and implications for nursing: It is concluded that the unitary approach focuses on identifying the client's pattern as a pathway to finding meaning in the situation. By incorporating the medical model within a unitary approach, OAPN students gain a renewed professional nursing identity.

Knowledge translation: The knowledge gained in the process of pattern recognition will make a significant difference in survivorship care and will contribute to the core of OAPN education.

Keywords: Cancer nursing; Advanced practice nurse; unitary approach; Margaret Newman; theory-based practice; nursing praxis

\section{Introduction}

Advances in medical technology accentuate the need to maintain a caring connection with clients. It is especially true in cancer nursing, a situation in which clients may experience pain, complications, and uncertainty related to treatment effects that clients undergo. Cancer nurses are in a position to establish a connection with clients at their most vulnerable time, thus helping them define their changing identity as cancer survivors [1].

As nursing educators involved with OAPN students, we seek to prepare graduates with knowledge that will enrich their practice and add to the value of health care delivery. Accordingly we have introduced Newman's [2,3] concept of health as expanding consciousness (HEC) as central to the master's OAPN curriculum. Reflective practice based on HEC provides opportunities for students to assist patients to recognize their own patterns of relationships and thus help clients find meaning in their situations. The concept of HEC emanates from a unitary, transformative perspective of nursing [4,5]. It provides a pathway to identifying clients' patterns and to helping clients find meaning in their situations. In addition, by incorporating the medical model within a unitary approach, OAPN students gain a renewed professional nursing identity.

\section{Background and Needed Directions of Cancer Nursing}

A few decades have passed since cancer has been re-conceptualized as a chronic illness characterized by episodic, acute morbidities. A prevailing trend in cancer nursing and its education is "survivorship care" [6-9]. The focus of cancer nursing, therefore, is related not only to diagnosis and active treatment but also to survivors' experience, which "goes beyond the disease and the response - or lack of response - to treatment" [1, p.28]. Certification under the leadership of the Oncology Nursing Society serves to cement specialization of cancer nursing. The focus of nursing in general is caring in the human health experience [5]. In cancer care, technological advances demand so much of nurses' energy for treatment-focused care that much of the nurses' time is devoted to the medical model. OAPN education, therefore, is becoming very complex in the incorporation of both medical and nursing models. Further elaboration of OAPN education is needed to clarify the students' professional identity with the nursing perspective [10-12]. Survivorship statistics call for an OAPN who focuses on the whole person-family living with cancer. It centers on the complex, dynamic process of the cancer experience, which may serve as a guide in finding meaning in the life experience. A shift to a unitary-transformative paradigm would help make the shift toward whole person-family care rather than the opposite.

The framework of Newman's $[2,3,4]$ theory of health as expanding consciousness (HEC) is helpful for this purpose. The theory asserts that the whole person-family is in the process of moving to higher levels of consciousness regardless of the presence of disease or disability, and this process is revealed in the evolving pattern of 
Page 2 of 5

interaction, both internal and external. Meaning is inherent in pattern, and vice versa. As the person gets in touch with what is meaningful in his/her life, the pattern emerges, and with it insight regarding potential action.

\section{Introducing a Unitary Approach in the OAPN Curriculum}

Nine OAPN students participated in a Master's two year program based on a unitary approach. Their background was practice in clinical settings dominated by cure-focused cancer care. In the first year of the program, they were working full-time or part time at the previous clinical settings. Most of them were given leaves of variable duration in the second year. They were accustomed to assessing and managing clients' problems from a medical perspective. The educators were two oncology nurse-teachers who were thoroughly versed in the concept of HEC. It was critical to introduce a nursing perspective at an early stage of the curriculum to allow a paradigmatic shift to occur based on HEC.

The curriculum was divided into two semesters for each year. During the first semester of the first year, the students learned theoretical perspectives, including paradigmatic issues from analytic to unitary ones, and then moved to Roger's [13] nursing conceptual model and Newman's $[2,3,4]$ theory.

\section{An OAPN's Application of HEC in Practice}

After learning the HEC perspective, the students had several opportunities to have dialogue in classroom on an OAPN's clinical practice. An OAPN skilled in the application of HEC in practice volunteered to join in dialogue with the students on the basis of her practice. We emphasized that the theory is a kind of lens in terms of a nursing perspective and the lens reflects the meaning of nursing phenomena. A given lens gives one meaning and another lens gives a different meaning on the same nursing phenomenon, resulting in a different assessment. We provided the students an opportunity to help them understand what difference HEC-based practice would make. The points for dialogue in class were: If you were a nurse in the same situation, how would you react or what would you do? Is there any difference between your and her perspectives in this situation? If there is what is it? What difference do you think would occur when a nurse is practicing within the context of HEC?

\section{A Case Presented by the OAPN}

Haru (a pseudonym), a single woman in her early 40's, was hospitalized in a palliative care unit because of advanced cancer. The patient and her family fervently wished to continue more chemotherapy treatment, but were discouraged because her physician informed them there would be no further benefit. She was struggling with total pain and denied to communicate with staff nurses. Her father showed up every day from early morning, but spent almost all the time on a chair at the end of the hallway. The nurses in the unit noticed that he did not come close to his daughter much, and when they were together, she talked to him as if she was angry with him. The nurses had a conference about this daughter-father interaction and no responses to nurses, but were unable to come up with any actions to alleviate the situation.

The OAPN concentrating on HEC was intentionally present when the father came close to his daughter; and invited him to sit down close to her. The OAPN also sat down with them, and for a while asked
Haru how she was feeling, but she did not respond. The father expressed his grief for his daughter's cancer as usual. The OAPN listened to and paid attention to his story, and when he became silent she asked the father, "Please tell me about the meaningful events and relationships with your daughter." He seemed upset a little bit, so she invited him to tell the story of her birth as his first girl baby. Then, he started to speak rapidly about her - how he was glad to have his baby as a girl, how he decided on his daughter's name, 'spring', how he was happy to receive a birthday present from her. He also explained that she was his stylist and always gave him her advice to help him look good.

Noting his rhythm and pace, the OAPN intentionally tried to sense the father's pattern reflecting his attentiveness to the chemotherapy treatment, his sympathy, and at the same time his love for his daughter. Haru did not move or say anything, but the OAPN sensed her comfortably participating in her father's story about her younger days. The OAPN sensed that the daughter's pattern and the father's pattern came close to each other, and their love for each other was being expressed. Before leaving, the OAPN expressed her thankfulness for the father's sharing and intentionally reminded Haru of her father's love. Haru did not move at all, but she whispered softly to the OAPN, "Come again, please!"

After this event, the nurses saw the father often sitting close to his daughter. He told the stories about his daughter to other nurses when they came to the room, and the daughter, even in painful condition, welcomed the nurses' visits. The staff nurses realized what difference the OAPN's presence had made in the daughter-father relationship.

The evolving patterns elicited through the OAPN's caring connection based on HEC were diagramed as changes from (1) a distant, non-verbal relationship between the patient and her father, and between the patient-father and the staff nurses because of the patient's anger with withdrawal, to (2) close communications between the patient and her father after the OAPN's invitation to tell their story and presence with them, and to (3) openness in the relationship between the patient-father and the staff nurses. The patient eventually connected with the environment (Figure 1).

The students focusing on the medical model said that they would have explained what was happening in her body and what she needed now was a stronger immune system within her body before further treatment. They acknowledged that this explanation might be important for cancer treatment; however it could not uncover the underlying issues in the patient-father's experience. A shift in perspective is needed in order to see the whole of the "human health experience" [5].

The key here was that the nurse and the patient-father can engage in the mutual process of expanding consciousness within a caring partnership [14]. The OAPN's deliberate invitation to the father to talk about their meaningful events and relationships helped them recognize how underlying issues in their lives was dominating their thinking [2]. The daughter and father were restricted with the thought on chemotherapy and could not find any meaning for their lives. Through the dialogue with the OAPN as a rich environment, they must have recognized their pattern, no meaningful interaction within them and even with the nurses, and at one time they must have found the action potential within their relationship. In this case, the moment of "pattern recognition" [2] was not clear; however their later attitude was clearly open with the environment, reflecting a change in their pattern. We would say that the daughter and father have recognized 
Page 3 of 5

the need to live on 'now' in new meaning for their lives through emancipation from the thought on chemotherapy. The change of the patient-father's pattern reached to the staff nurses' pattern and a new pattern evolved in the nursing setting.

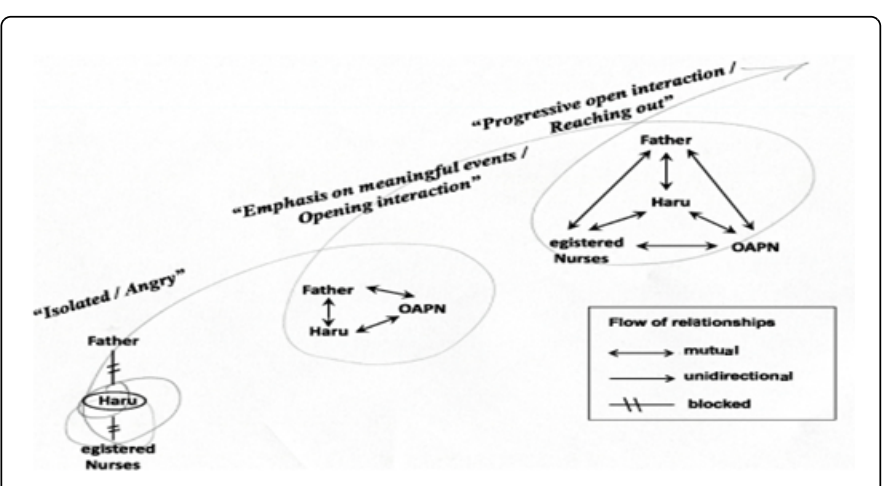

Figure 1: Evolving patterns through the OAPN's connection

Through repeated dialogue in class, the students came to grasp the differences between their accustomed perspective in their clinical settings and the new perspective based on HEC. The most obvious aspect of the pattern of the daughter and the father's relationship was separation. Within HEC in the unitary paradigm, a patient is undividable and inseparable from her/his family [2]. Wholeness of a patient-family is identified in pattern. Pattern is defined as "information that depicts the whole, understanding of the meaning of all the relationships at once" [2,p.71]. The OAPN recognized the whole daughter-father pattern and intended to provide an opportunity for them to become closer.

The daughter-father reached a new awareness of their relationship and got new meaning for their lives. This phenomenon was an example of health as expanding consciousness regardless of the presence of disease [2]. The staff nurses also experienced themselves as expanded consciousness in caring connections with the daughterfather. In the unitary paradigm, all relates to each other, so the pattern of father connected with that of daughter, and the pattern of daughterfather penetrated into the larger pattern of the practicing nurses' group in the nursing unit.

\section{An OAPN Student's Reflective Practice}

The OAPN students entered into the exercise in the second semester of the first year. They had an assignment to work with their clients with complicated issues related to the cancer experience and to reflect on their ability to recognize the pattern of clients. The following vignette illustrates a student's reflective practice: her sensing separation in relationship between the patient and the parents; her intended invitation to them to tell their meaningful things in their lives and being with them; her acknowledgement of the patient-parents' pattern change from incompatibility to openness in relationship and their movement toward a potential action.

The student's patient-family was a woman in her 40's and parents in their 80 's. The patient was at the end stage of cancer and suffering from insomnia. Her parents were suffering grief at their loved daughter's situation. The student wanted to help them and tried to understand their pattern intentionally in daily care.
The patient did not talk at all and looked as if she 'closed off' so as not to give any worry to her parents. On the other hand, her parents were worrying about her because they did not know her desire. One day, the parents told the student, "I am very painful, because our loved daughter's appearance has become so altered. We don't want others to look at her." The student strongly urged the daughter to express her desire and the parents to be released from the worry about her altered look. The student asked them to tell about meaningful things in their family, and tried to be present with them. They told their stories for a while and enjoyed it. Afterward the daughter said, "I had a hard time since I got cancer, and you too. I am now thinking about my death," and invited her parents to talk about it too. In this unfolding process, the student sensed that the daughter became open and the parents became open too. The student thought that they might have recognized their pattern, though she did not ask what meaning they got from the pattern at the moment. Within a few days, the student heard that the parents were calling her friends to come and see their daughter. The student sensed that the pattern of the parents and that of their daughter connected with each other and became ONE. The student was very thankful for connecting with them, trusting power within themselves, and caring for them attentively.

The students understood that being with clients and actively caring in their health experience through dialogue could lead them to pattern recognition and it made a difference for the meaning of their lives. The students also clearly realized that this nursing care requires a strong compassionate motivation to assist clients and courage to take a step forward. It is a manifestation of students' intentions and appreciation for caring partnership from the HEC perspective.

Each student's experience on HEC-based practice was helpful to other students. The students articulated that previously they had made efforts for curing cancer or alleviating symptoms, and they had considered that 'what I should do as a nurse.' Through the theory of HEC, they began to focus on identifying clients' patterns and on understanding the meaning of these patterns. There were big differences after the students incorporated the theory of HEC, because their intentions for actions were different. So, the meaning of nursing care was different. They saw clearly the difference between nurses' attitude and actions in the medical model and those in the nursing model. The nursing perspective and intention in survivors care transforms their practice.

\section{Another OAPN Student's Resonating Experience}

A student's patient-family was the father and the mother in their 40 's, and their two children in high school. The father diagnosed with advanced cancer was deeply troubled with his physical condition because of no sign of recovery. The parents loved their children and valued living with them as a whole family. The student's experience of her mother's passing when she was in high school deeply remained in her mind as an unsolved conflict, because her parents did not tell her about her mother's cancer.

At the 1st meeting, the parents attended without their children. This fact disappointed the student. But she encouraged herself and asked the parents, "Please tell me about the meaningful events or relationship in your family." The parents talked a lot of enjoyable memories with the children in details. With the birth of the 1st baby, they were very glad because it happened in the 5th year after their marriage and enjoyed parenting together. After the birth of the 2 nd child, they had the happiest years in raising the children. To spend 
Page 4 of 5

more time with their children, the father moved to an easier job and the mother quit her job too. They committed to their children's school lives and events. They said that the most meaningful thing was being with them. But an issue was that they had not told the children the truth about the father's cancer, because he did not want to do so. The mother was following his opinion. He just repeated about his wishes not to bother the children's school lives. After the meeting, the student drew a family life diagram following the story. It was filled with enjoyable events and authentic relationships in the family, and then followed by a collapse of these relationships by cancer diagnosis (Figure 2).

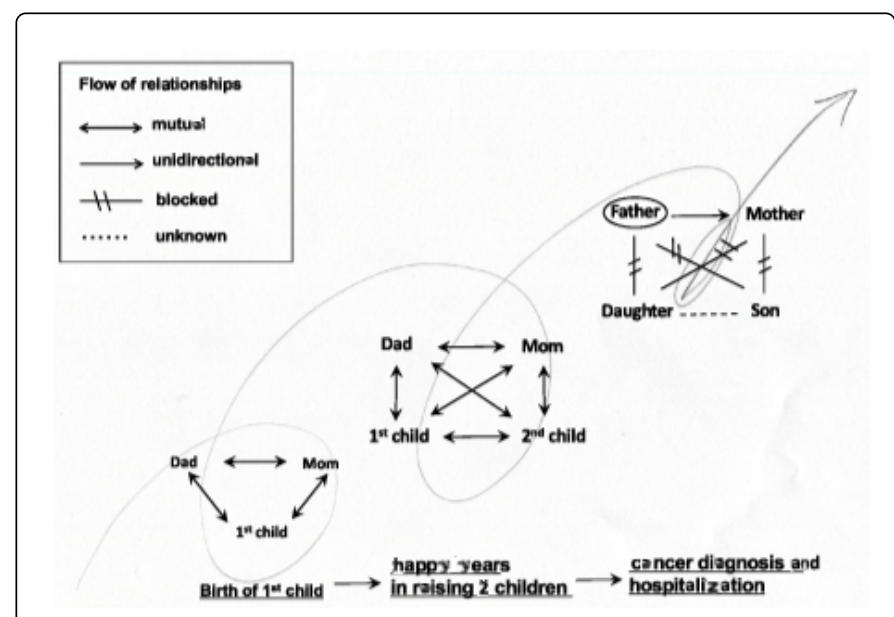

Figure 2: Part of a diagram used in nursing praxis

At the 2nd meeting, the children did not show up again. The student shared the diagram with them. The father said, "I wonder what my children are thinking about my hospitalization. They do not worry about it much? Or in spite of many worries, they cannot speak about it?" The student wondered about their thought, but couldn't ask them directly. The student recognized that his perspective moved from the point of his own to that of their children. The student was convinced that pattern recognition happened to him. Then, the student plunged forward into dialogue from her perspective. Feeling their love for the children, she urged them to tell about the true situation to the children in order to speak more frankly with each other. After the meeting, the student felt very sick. She realized that she had been too invasive and yet she was speaking from the center of her truth.

At the 3rd meeting, the student recognized that the parents had talked to each other after the 2nd meeting and had gotten deeper understanding of their pattern restricting openness with children. The father said, "We learned many things from different perspectives through dialogue. We appreciated it." He continued, "But, we do not want to tell our children about my cancer now. Later we may change our decision, but not now." In listening to their decision, the student clearly realized that she had entered into dialogue with the family with her own agenda, and had confused it with her own situation. At the same time, the student understood how much her parents had loved her as well as these parents did. This was part of the student's transformation. The student realized that it should not be the issue to tell the truth to the children or not to tell, but the important thing was for them to understand their situation. Gaining this understanding, the student felt truly free. The student wrote, "Our partnership became more flexible and I was convinced that my pattern was resonating with theirs." About one month after the termination of this partnership, the student received an email from the clients. They wanted to talk with her again.

The evolving patterns of the clients in process of nursing praxis were not necessarily what the students expected, illustrating the nonpredictability of HEC. But every client and student recognized a personal pattern and found potential actions in the resonating process. This experience made a difference in the students' lives as well as clients' lives. The students understood that this intervention, led by HEC, added special value to their practice. The research components of praxis yield a retrospective interpretation of the data as it relates to the theory.

\section{Students' Awareness of Own Bias in Practice}

Some students realized that the focus of their practice was symptom managements and investigations of the effects of the medical interventions. Others realized that 'a patient had been merely one of many' and they had not related to each patient intentionally. Some students confessed that the relationship with patients was superficial; they avoided spending energy in relating because of the busy clinical setting. Others said they did not know how to relate to patients meaningfully, and added they tried to listen to them and to understand them, but the students' own perspectives dominated their thinking. All students realized that the important thing in nursing was the process of relating with clients.

The students presented the relationships between clients and themselves in concrete situations and came to find meaning in these situations from the HEC perspective. When patients' conversation and/or behaviors were not clear, they thought patients were striving toward a self organizing process and the students then assisted them to recognize their pattern. When patients became open to interaction with others, this behavior was interpreted as reaching a turning point of potential action [2].

At the same time, the students became more honest and more open with clients. They knew their openness linked with clients' openness. This interaction led to increasing ability to sense clients' pattern and to enhancing the capacity to understand clients as a whole. When they concentrated on the evolving pattern, even a small change became apparent and they could sense the emerging clarity. The student learning process was individual. Some took longer than others and needed more experiences.

\section{Nursing Praxis}

Newman [4] emphasized that the ability to envision the unitary nature of human beings and the evolving process of moving to higher consciousness must be demonstrated in terms of how this makes a difference in our practice. This view shapes a new type of nursing intervention that focuses on the whole client and serves to find the meaning in the health experience. This intervention followed Newman's proposal of "HEC Praxis: the Process of Pattern Recognition" [4, pp. 89-91], and in this approach the OAPN students conducted a case study as nursing praxis. Praxis "involves the merging of a priori theory, research and practice" [4,p.21]. The HEC provides the theoretical orientation, and research takes the form of a retrospective interpretation of practice. This experience occurred in our curriculum in the first semester of the second year. 
Page 5 of 5

With each encounter with the patient and /or family, the student tried to build a good relationship with them and entered into a partnership in daily nursing practice. Choosing an appropriate time, each student asked, "Tell me about your meaningful relationships or events in your lives". If the patient and/or family asked, the student suggested telling about an important memory in childhood. Every student tried to be an active listener, sometimes prompting, "Tell me more about it". When the right time came to end for the first meeting, they stopped and made an appointment for the next. A promise was made to draw a diagram of the client's life pattern and to share it.

When it is necessary, we met each student to share the diagram which each drew at home and to give suggestions. In doing so, an important thing was that each student captured the patient-family's pattern and was sensitive as the pattern changed. The next thing was the students draw the diagram of configuration of their life process. The students responded quickly to our suggestions as to how to draw meaningful diagrams [15]. We believed the above process was important for the early learning process of this nursing intervention. After the second meeting, the students actively moved on in partnership process with the patient-family.

The aim was that the students would fully experience the process of "the coming together of nurse and patient, the resonance pulsating as ONE in pattern recognition, and the transformation that takes place as they moved apart" [4, p. 35]. We believe that through this experience the students would evolve to a higher level of consciousness by shifting from traditional care based on the medical diagnosis and treatments of cancer toward unitary nursing care. Then all that they were doing in the clinical settings would have meaning from the perspective of the nursing model of caring partnership with clients.

\section{Conclusion: OAPN Students Education on HEC-based Practice}

This paper demonstrated an approach for OAPN students education based on Newman's theory of health as expanding consciousness $[2,3,4]$. What the students learned was that HEC-based practice incorporates the problem solving approach to clients with cancer which they had been accustomed to, goes beyond it within the unitary approach, and helps clients make differences in their lives. The students realized that the key is to identify clients' pattern as a whole and to devote selves for clients to get in touch with what is meaningful in their lives.
In the process of implementing the new curriculum, OAPN students and educators resonated with the same values and beliefs that the nurse-patient relationship is the essence of the ontology of the nursing discipline, and that clients in the cancer experience are viewed as a whole. The HEC theory opens a unitary perspective and actions, and facilitates OAPN students toward a caring connection with the whole client. Even in the health care arena where nursing care revolves around cancer diagnosis and treatment, OAPNs need to be grounded in the nursing domain.

\section{References}

1. The National Coalition for Cancer Survivorship (1998). A cancer information guide, Maryland: Author.

2. Newman MA (1986) Health as expanding consciousness. St. Louis: The C. V. Mosby Company.

3. Newman MA (1994) Health as expanding consciousness (2nd Ed.). Sudbury, MA: Jones and Bartlett (NLN Press).

4. Newman MA (2008) Transforming presence: The difference that nursing makes. Philadelphia: E.A. Davis Company.

5. Newman MA, Sime AM, Corcoran-Perry SA (1991) The focus of the discipline of nursing. Adv Nurs Sci 14: 1-6.

6. Ferrell BR, Winn R (2006) Medical and nursing education and training opportunities to improve survivorship care. J Clin Oncol 24: 5142-5148.

7. Grant M, Economou D, Ferrell BR (2010) Oncology nurse participation in survivorship care. Clin J Oncol Nurs 14: 709-715.

8. Irwin M, Klemp JR, Glennon C, Frazier LM (2011) Oncology nurses' perspectives on the state of cancer survivorship care: current practice and barriers to implementation. Oncol Nurs Forum 38: E11-19.

9. Klemp JR, Frazier LM, Glennon C, Trunecek J, Irwin M (2011) Improving cancer survivorship care: oncology nurses' educational needs and preferred methods of learning. J Cancer Educ 26: 234-242.

10. Grant M, Economous DD (2010) Survivorship education for quality cancer care. Oncology Issues, May/June, 48-49.

11. Shearer D, Adams J (2012) Evaluating an advanced nursing practice course: student perceptions. Nurs Stand 26: 35-41.

12. White KR, Coyne PJ (2011) Nurses' perceptions of educational gaps in delivering end-of-life care. Oncol Nurs Forum 38: 711-717.

13. Rogers MA (1970) An introduction to the theoretical basis of nursing. Philadelphia: F. A. Davis.

14. Newman MA (2002) Caring in the human health experience. International Journal for Human Caring 6: 8-12.

15. Endo E, Nitta N, Inayoshi M, Saito R, Takemura K, et al. (2000) Pattern recognition as a caring partnership in families with cancer. J Adv Nurs 32: 603-610. 